\title{
A PRODUÇÃO DAS IDENTIDADES/DIFERENÇAS PELA PEDAGOGIA DA ALTERNÂNCIA NO CEFFA DE JI-PARANÁ/RO
}

\author{
LA PRODUCCIÓN DE LAS IDENTIDADES / DIFERENCIAS POR LA \\ PEDAGOGÍA DE LA ALTERNANCIA EN EL CEFFA DE JI-PARANÁ/RO
}

\section{THE PRODUCTION OF IDENTITIES/DIFFERENCES BY THE PEDAGOGY OF ALTERNATION AT CEFFA IN JI-PARANÁ/RO}

\author{
Alberto Dias Valadão ${ }^{1}$ e José Licínio Backes ${ }^{2}$ \\ ${ }^{1}$ Fundação Universidade Federal de Rondônia, Ji-Paraná/RO, Brasil \\ ${ }^{2}$ Universidade Católica Dom Bosco, Campo Grande/MS, Brasil
}

\begin{abstract}
RESUMO: O artigo analisa o processo de produção das identidades/diferenças no contexto da Pedagogia da Alternância. O estudo está inscrito nos Estudos Culturais, em sua interface com a Psicologia Social. No primeiro momento, argumenta-se que as identidades/diferenças não são naturais, mas produzidas; no segundo, mostram-se os caminhos investigativos e instrumentos utilizados (entrevistas, observações e análise de documentos curriculares); por fim, apresentam-se os resultados, que indicam que a Pedagogia da Alternância, ao ter como objetivo valorizar o sujeito do campo e sua identidade, produz algumas diferenças como indesejáveis e desviantes, portanto, a serem corrigidas ou excluídas.
\end{abstract}

PALAVRAS-CHAVE: Pedagogia da Alternância; Identidade; Diferença.

RESUMEN: El artículo analiza el proceso de producción de las identidades/diferencias en el contexto de la Pedagogía de la Alternancia. El estudio está inscripto en los Estudios Culturales, en su interfaz con la Psicología Social. En primer momento, se argumenta que las identidades/diferencias no son naturales, sino producidas; en el segundo, se muestran los caminos investigativos e instrumentos utilizados (entrevistas, observaciones y análisis de documentos curriculares); finalmente se presentan los resultados, que indican que, al tener como objetivo valorizar al sujeto del campo y su identidad, la Pedagogía de la Alternancia produce algunas diferencias como indeseables y desviantes, y por lo tanto, deberán ser corregidas o excluidas.

PALABRAS CLAVE: Pedagogía de la Alternancia; Identidad; Diferencia.

ABSTRACT: This paper analyzes the process of production of identities/differences in the context of the Pedagogy of Alternation. The study is situated in the field of Cultural Studies, in its intersection with Social Psychology. Firstly, it is argued that identities/differences are not natural; rather, they are produced. Secondly, the investigation paths and the instruments used (interviews, observations and analysis of the curriculum documents) are presented. Finally, the results are shown, evidencing that the Pedagogy of Alternation, whose objective is to value the rural subjects and their identity, has produced some differences as undesirable and deviant, hence, they should be either corrected or excluded.

KEYWORDS: Pedagogy of Alternation; Identity; Difference. 


\section{Introdução}

O artigo tem como objetivo analisar o processo de produção das identidades/diferenças no contexto da Pedagogia da Alternância. Argumenta-se que a Pedagogia da Alternância, ao ter como objetivo valorizar o sujeito do campo e sua identidade, produz algumas diferenças como indesejáveis e desviantes, portanto, a serem corrigidas ou excluídas.

Para o desenvolvimento da argumentação, recorre-se ao campo dos Estudos Culturais, vendo-se nele, dada sua característica interdisciplinar, uma aproximação com a Psicologia Social, além de se considerar que ambos os campos consideram o sujeito como constituído por práticas sociais. Com base nessas teorizações, analisam-se os dados de uma pesquisa de campo realizada no Centro Familiar de Formação por Alternância (CEFFA) de Ji-Paraná/Rondônia. Trata-se de uma proposta implementada em Rondônia, no final da década de 1980, que se afirmou junto aos agricultores como uma alternativa à escola urbana, vista como inadequada por ignorar a realidade do campo. A Pedagogia da Alternância postula que a educação e a formação estão relacionadas com questões com as quais a família trabalha, portanto, pautadas na realidade cotidiana familiar, social e profissional vivida pelos jovens que residem longe dos centros urbanos. Essa pedagogia, mediante seus instrumentos pedagógicos, procura fazer a ligação entre momentos vividos na família e momentos vividos no ambiente escolar, em um regime de internato (Nosella, 2014), construindo sujeitos com determinadas identidades. Porém, ao proceder dessa forma, como se argumenta, também produz diferenças.

O foco central deste artigo não é trazer o que já foi pesquisado sobre a Pedagogia da Alternância, mas é importante apontar sucintamente as questões centrais problematizadas por seus teóricos, com destaque para Gimonet (2007), García-Marirrodriga e Puig-Calvó (2010), Nosella (2013, 2014), Puig-Calvó e Gimonet (2013) e Queiroz (2013). Segundo esses autores:

1. A Pedagogia da Alternância busca a formação integral das pessoas por meio de um processo educativo que alterne o tempo da escola com o tempo de trabalho na família e na própria instituição, possibilitando que os pais, organizados em associações, participem ativamente no processo formativo dos alunos.

2. Trata-se de uma Pedagogia voltada para a realidade do campo, portanto, deve pautar-se em um currículo que considere essa realidade e que contribua para a permanência dos jovens no campo, tornando-se líderes no desenvolvimento de suas localidades e na luta coletiva pela garantia de seus direitos.

3. Além de um currículo voltado para a realidade do campo, na Pedagogia da Alternância, entende-se que sua implementação depende da presença de monitores, que, mais do que professores, que educam e formam, têm a responsabilidade de coordenar, acompanhar e animar o projeto educativo em toda a sua extensão.

4. A Pedagogia da Alternância conta com uma história rica de experiências e, ao longo dos anos, tem atentado para as transformações da vida dos jovens do campo. Nesse sentido, embora a realidade do campo continue mantendo suas especificidades, no contexto atual, não se pode ignorar que as fronteiras entre a vida dos jovens do campo e dos jovens da cidade têm ficado mais porosas, sobretudo em função dos meios de comunicação, que disseminam comportamentos e valores urbanos que atingem os jovens do campo. Isso coloca novos desafios para a Pedagogia da Alternância, para que os jovens efetivamente possam e queiram manter-se no campo. Nesse sentido, a Pedagogia da Al- 
ternância continua sendo uma alternativa vigorosa de educação para os jovens do campo e uma forma de lutar contra o histórico descaso do Estado brasileiro para com essa modalidade de educação.

Essas características estão presentes no CEFFA de Ji-Paraná, contexto da pesquisa, que é administrado por uma associação promocional formada pelas famílias dos alunos e pelos monitores (como são chamados os professores). No ano de realização da pesquisa (2016), atendia em torno de 200 alunos do município de Ji-Paraná e de quase duas dezenas de municípios menores. Dentre os envolvidos com esse projeto educativo, escolheram-se como sujeitos da pesquisa aqueles que mais diretamente vivem em seus corpos os efeitos da Pedagogia da Alternância: alunos e monitores. Ouvindo-se e observando-se a forma como a Pedagogia da Escola afeta tais sujeitos e como são interpelados por ela, fez-se a escolha aleatória de 20 alunos, dos 39 matriculados no $4_{-}^{\circ}$ ano do Ensino Médio, articulado com a Educação Profissional Técnico em Agropecuária, e de oito dentre os 19 monitores que participam das ações pedagógicas na Pedagogia da Alternância. Para a escolha dos monitores, consideraram-se: (a) homens e mulheres; (b) diferentes disciplinas; (c) diferentes trajetórias de formação; (d) diferentes tempos de trabalho no CEEFA; (e) monitores com contrato de trabalho efetivo. Quanto aos alunos, foram escolhidos os do $4_{-}^{\circ}$ ano, por terem o maior tempo de estudo no CEFFA de Ji-Paraná, portanto, um maior conhecimento sobre a Pedagogia da Alternância.

Esclarece-se que, neste artigo, em função da limitação de espaço, serão citadas apenas as falas de sete monitores e seis alunos (todos referenciados com pseudônimos), mas as demais falas vêm ao encontro das aqui citadas.

Para discutir como a Pedagogia da Alternância vai constituindo as identidades e diferenças, o artigo está estruturado em três momentos interdependentes. Inicia-se mostrando os Estudos Culturais como campo teórico que dissipou as fronteiras entre Educação e Psicologia, e argumenta-se que as identidades/diferenças não são naturais e essenciais, mas produzidas. Em um segundo momento, aponta-se como o procedimento de investigação foi construído e refeito no transcorrer da pesquisa de campo, descrevem-se os instrumentos utilizados, e apresentam-se as características do contexto no qual se situa o CEFFA e o perfil dos monitores. No terceiro momento, discute-se como a Pedagogia da Alternância opera no sentido de produzir identidades/diferenças. Por fim, trazem-se a síntese dos resultados e outros apontamentos.

\section{Os Estudos Culturais e a Psicologia Social: as identidades e dife- renças como produção}

Tanto os Estudos Culturais quanto a Psicologia Social são campos caracterizados como interdisciplinares, o que permite sua articulação na análise do processo de construção das identidades/diferenças. Com o objetivo de "perceber as intersecções entre as estruturas sociais, os grupos sociais, a cultura, a história e as relações que as pessoas constroem e passam a ser construídas por elas", como afirmam Guareschi, Medeiros e Bruschi (2013, p. 31), a Psicologia Social não se configura como uma disciplina, mas como uma esfera plural do conhecimento.

De modo semelhante, os Estudos Culturais veem a cultura como algo profundamente subjetivo e pessoal (Hall, 2013), atribuindo importância ao contexto no qual ocorre a ação 
social. Nessa perspectiva, a cultura é, antes de qualquer coisa, interpelativa, produzindo subjetividades (Bernardes \& Hoenisch, 2013), representando, tanto a partir dos Estudos Culturais quanto da Psicologia Social, o enfraquecimento dos limites tradicionais entre as disciplinas e possibilitando o crescimento de modos de fazer pesquisas interdisciplinares. Por isso, entende-se que, mesmo que o foco maior neste artigo esteja nos Estudos Culturais, ele se direciona também à Psicologia Social.

Os Estudos Culturais surgem promovendo abalos na teoria cultural nos meados do século XX na Inglaterra, com a preocupação de colocar em xeque o conceito de cultura ligado à erudição, à “alta” tradição literária e artística, defendendo a ideia de cultura como central na constituição de todos os aspectos da vida social e no questionamento radical de que há uma alta e uma baixa cultura. Até então, aceitava-se que havia uma cultura elitista dominante - produtora de verdades incontestáveis e universais -, em detrimento de uma cultura de massa, popular, caracterizada pela barbárie e pela incapacidade intelectual, social e política, necessitando, dessa forma, dos detentores de uma "alta cultura" para organizar, moralizar e fixar os significados que circulariam como necessários e indispensáveis para todos. Junto com esse questionamento, veio também a mudança de compreensão das identidades/diferenças, que deixam de ser vistas como biológica e naturalmente definidas e passam a ser entendidas como construções históricas, sociais e culturais.

No que tange à identidade e à diferença, algumas questões tornaram-se objeto de estudo e reflexão a partir de pesquisas sobre raça, etnia, gênero, modernidade e pós-modernidade, dentre outras temáticas, o que permitiu o deslocamento do foco da identidade e da diferença vistas como um conjunto de referências estáveis e sedimentadas, seja pela herança biológica, seja pela referência histórica (ancestral comum), para um prisma em que a cultura e o social são o chão sobre o qual são construídas.

A importância dessa virada é que se rompe com a noção de que existe uma identidade unificada, completa, duradoura. Afirma-se a ideia de que as identidades hoje são cada vez mais fragmentadas e fraturadas, construídas ao longo dos discursos e na relação com as diferenças, em constante processo de mudança (Hall, 2012). Com a ampliação dos sistemas de significação e representação, há uma pluralização das identidades e das diferenças, ambas vistas agora como contingentes, efêmeras. Como afirma Silva (2012, p. 91),

A identidade e a diferença são estreitamente dependentes da representação. É por meio da representação, assim compreendida, que a identidade e a diferença adquirem sentido. É por meio da representação que, por assim dizer, a identidade e a diferença passam a existir. Representar significa, neste caso, dizer: "essa é a identidade", "a identidade é isso".

Os Estudos Culturais, portanto, ao operarem com processos sociais e práticas culturais que constituem as diferentes posições de sujeito, permitiram, inclusive, a articulação com o campo da Psicologia Social. Ambos os campos de conhecimento reconhecem que seus limites e demarcações não são rígidos, mas cruzam-se, sobretudo por procurarem entender a construção das identidades e diferenças dos sujeitos a partir de seus diferentes significados e práticas sociais e culturais.

Nessa perspectiva, pensar a Pedagogia da Alternância a partir dos Estudos Culturais é vê-la como um campo de luta pela imposição de significados, é entender que as identidades e diferenças com as quais se trabalha não são seres da natureza, mas resultados de 
práticas de significação (Silva, 2010), em um processo ininterrupto de contestação, negociação e transformação, como diz o autor. Nesse processo de construção de identidades e diferenças incertas, imprevisíveis, em que as relações de poder controlam a produção de significados, a linguagem torna-se um operador importante, modelando práticas sociais e pondo novas práticas em funcionamento (Hall, 1997).

O significado constrói-se na linguagem e por meio dela, como afirma Hall (2016). Para compreender como a Pedagogia da Alternância vem produzindo identidades e diferenças, atentou-se à ideia de que os "significados só podem ser compartilhados pelo acesso comum à linguagem” (Hall, 2016, p. 17). Apesar de invocar a linguagem como um dos meios pelos quais pensamentos, ideias e sentimentos são representados no contexto educativo do CEFFA, sendo ela essencial aos significados produzidos pelos sujeitos que ali estudam e trabalham, entendeu-se como necessário também trabalhar com a ideia de discurso. Isso porque a prática pedagógica da Escola e as práticas realizadas pelos seus sujeitos somente ganham sentido e se tornam objetos do conhecimento dentro do discurso, assim como por meio dele produzem o conhecimento (Hall, 2016).

Essa ênfase dada à linguagem e ao discurso torna-se importante, pois, mesmo que esses termos tenham sido marcados por impermanências, eles permitem compreender que tanto a identidade quanto a diferença "estão estreitamente ligadas a sistemas de significação. A identidade é um significado - cultural e socialmente atribuído. A teoria cultural recente expressa essa mesma ideia por meio do conceito de representação" (Silva, 2012, p. 89).

Propor um estudo sobre a produção das identidades e diferenças na Pedagogia da Alternância requer, então, pensar que os sentidos produzidos mediante práticas de significação vão produzindo sujeitos classificáveis entre desejáveis e indesejáveis, normais e desviantes. Essas práticas, em função do contexto onde vivem os sujeitos, têm efeitos contingentes, hesitantes, em vista da posição ocupada por esses sujeitos nas relações de poder que os constituem.

\section{Os (des)caminhos da investigação}

O desenvolvimento da pesquisa com o campo teórico escolhido mostrou a necessidade de encontrar alguns caminhos. Sabendo-se da impossibilidade de dar conta de todas as ações que envolvem as práticas dos sujeitos dessa Pedagogia, foi preciso fazer algumas opções.

Como destacado na introdução, a pesquisa foi realizada no CEFFA de Ji-Paraná, no estado de Rondônia. Como resultado da política estatal de colonização e povoamento, a criação do estado de Rondônia, em 1982, atraiu agricultores e sem-terra de diferentes regiões do Brasil, entre outros, com a promessa de que ali teriam sua própria terra, produziriam com fartura e teriam uma vida digna. Entretanto, a realidade é que alguns "colonizadores” foram se apropriando de grandes extensões de terras. Aos demais trabalhadores, is to é, os agricultores de subsistência de Rondônia, cujas propriedades não foram tomadas mediante coação/repressão ou persuasão (Souza, 2014), restou venderem seus produtos por preços irrisórios ou venderem suas terras por preços muito aquém do valor de mercado na região. Isso causou embate, principalmente porque, para o agricultor familiar, sua 
terra "não tem preço". Por isso, os agricultores reagiram, criando associações e cooperativas, além de participarem do Sindicato dos Trabalhadores e Trabalhadoras Rurais (STTRs), ou seja, mobilizaram-se em busca de políticas que reconhecessem suas identidades e sua cultura, incluindo políticas educacionais. "Em suas lutas por identidades positivas, afirmativas, contestam e se contrapõem a essa função das políticas de perpetuar sua inferiorização porque diferentes" (Arroyo, 2014, p. 296).

Hoje, além da capital, Porto Velho, com uma população estimada em 502.748 habitantes em 2015, e de Ji-Paraná, com uma população estimada em 131.560 habitantes no mesmo ano, há outros 50 municípios, cuja população média é de 22.700 habitantes (IBGE, 2014). Desses municípios, segundo o Censo do IBGE de 2010,22 têm mais de $50 \%$ da população residindo no campo, com alguns municípios, como Alto Alegre dos Parecis, Campo Novo de Rondônia, Corumbiara, Governador Jorge Teixeira, Ministro Andreazza, São Felipe do Oeste e Vale do Paraíso, com uma população camponesa superior a 70\%; em Novo Horizonte do Oeste e Theobroma, mais de $80 \%$ da população vivem no campo.

Nesse contexto, a Pedagogia da Alternância tem sido vista como uma opção para os jovens do campo se formarem sem que sejam obrigados a buscar alternativas na cidade, que, no contexto do estado de Rondônia, são escassas. Há pouco trabalho disponível na cidade, e o jovem, quando vai para a cidade, além de ser discriminado, geralmente acaba sem emprego, vivendo em condições mais precárias ainda do que no campo.

Cabe, ainda, apresentar as características dos monitores participantes da pesquisa.

Monitora Ana: fez Ensino Fundamental e o curso de Nível Médio articulado com Educação Profissional Técnico em Agropecuária nos CEFFAs de Vale do Paraíso e Ji-Paraná. Cursou graduação em Ciências Biológicas em uma instituição particular e atua há anos como monitora, ministrando a disciplina de Agroecologia. Ela optou pela Pedagogia da Alternância por ser egressa e entender que é a melhor opção de educação para os filhos de agricultores do interior de Rondônia. Fez, ainda, uma parte do curso de formação específica para atuar na Pedagogia da Alternância.

Monitor Marcos: graduado em Agronomia. Atua há um ano no CEFFA e não fez nenhuma formação para trabalhar na Pedagogia da Alternância. Ministra as disciplinas Planejamento e Empreendedorismo, e Agricultura. Optou pela Pedagogia da Alternância por falta de opção profissional.

Monitor Sérgio: formado como Técnico em Agropecuária e cursando Agronomia. Está há dois anos no CEFFA e não teve formação para trabalhar com a Pedagogia da Alternância. Ele ministra apenas uma disciplina do Módulo Produção Vegetal e é responsável pela busca de locais de estágio para os alunos. Sérgio optou pela Pedagogia da Alternância porque sempre teve vontade de estudar no CEFFA quando era mais novo, mas não conseguiu por falta de interesse de sua família.

Monitora Regina: pedagoga, ex-professora de escola pública, onde trabalhou por seis anos. Ela está no CEFFA Escola há 10 anos, fez o curso de Formação de Monitores na Pedagogia da Alternância e uma especialização nesta modalidade educativa pela UFMG. Ministra Arte, e História e Geografia do Estado de Rondônia. Optou pela Pedagogia da Alternância por ter certeza de que preenche o perfil para ser monitora, pois deseja formar a consciência crítica nos alunos.

Monitora Sara: pedagoga, ex-professora de escola pública, onde trabalhou por quatro anos. Está no CEFFA há dois anos e não fez o curso de Formação de Monitores na 
Pedagogia da Alternância. Sara optou por trabalhar no CEFFA por gostar da proposta da Escola e do trabalho com a Pedagogia da Alternância. Ministra as disciplinas de História e Geografia.

Monitor Carlos: graduado em Agronomia, não tinha experiência como professor antes de entrar no CEFFA, ministra as disciplinas de Gestão em Agropecuária, e Culturas Anuais e Perenes. Carlos é efetivo, contratado pela Associação Promocional da Escola Família Agrícola Itapirema de Ji-Paraná (APEFAIJIP) e trabalha no CEEFA por tratar-se de uma escola que tem qualidade e seriedade no trabalho realizado e por poder contribuir para formar cidadãos, com respeito e ética.

Monitor Nivaldo: recém-graduado do curso de Engenharia Ambiental, está há menos de um ano na Pedagogia da Alternância e fez todo o Ensino Fundamental, Médio e Técnico nos CEFFAs. Por ser ex-aluno da Escola e, segundo ele, por ser considerado um ótimo aluno, foi convidado para ser monitor, mas não fez nenhuma formação para atuar como tal. Atua no CEFFA porque este valoriza, divulga e promove a agricultura familiar.

Salienta-se que todos os monitores citados neste artigo são efetivos e foram contratados pela Associação Promocional da Escola Família Agrícola Itapirema de Ji-Paraná (APEFAIJIP). Além de ministrar aulas, o monitor faz acompanhamento personalizado dos alunos; orienta e acompanha os projetos, tanto profissionais, quanto de estágio; e ainda se responsabiliza, junto com os agricultores, pela gestão do movimento.

Definidos o local e os sujeitos da pesquisa, faltava definir os instrumentos investigativos por meio dos quais os dados seriam produzidos a partir dos sujeitos selecionados. Os instrumentos que abriram as possibilidades de movimentar o campo social escolhido foram definidos no decorrer da pesquisa. As perguntas feitas desencadeavam buscas que engendravam várias possibilidades de respostas, criando chances de se fazerem outras tantas perguntas, em um processo sem fim (Meyer \& Soares, 2005).

Elegeram-se para a produção de dados: a entrevista com alunos e monitores; a observação de alunos, de monitores, da inter-relação destes com os outros sujeitos e do ambiente acadêmico onde estão inseridos; e a análise dos instrumentos pedagógicos e curriculares da Pedagogia da Alternância com os quais alunos e monitores se inter-relacionam. Nesse processo investigativo, que ocorreu de fevereiro a novembro de 2016 , não houve uma moção a priori prevista para análise dos dados, mas, na descrição dos trajetos percorridos, foram aparecendo os efeitos da cultura do CEFFA de Ji-Paraná, que, sob o olhar dos Estudos Culturais, em meio a relações de poder, foram adquirindo diferentes significados, assim constituindo diferentes sujeitos. Nesse sentido, tanto as entrevistas quanto os outros instrumentos não foram vistos como neutros e desinteressados, mas como algo produzido na relação entre pesquisador e pesquisado.

Em relação à observação, atentou-se para novas questões que emergissem. Procurava-se localizar, como apontam Meyer e Soares (2005), novos ângulos de observação. Assim, viu-se a necessidade de desenvolver a sensibilidade e a habilidade para ver e escutar, sabendo-se que na pesquisa há imprevistos e interrupções, o que fomentaria ainda mais dúvidas sobre como estão se produzindo os sujeitos dos CEFFAs. Essa vulnerabilidade e instabilidade são marcas com as quais este trabalho foi se constituindo, entendendo-se que visibilizá-las faz parte do rigor de uma pesquisa dentro do campo teórico dos Estudos Culturais.

Salienta-se que, ao realizar-se a análise de documentos curriculares do CEFFA, tais como o Projeto Político Pedagógico (PPP) e o Plano de Curso (2014), estes começaram a 
ser vistos como produção independente dos contextos culturais em que os alunos estão inseridos, tendo sido propostos pela coordenação pedagógica apenas como necessários à existência da Pedagogia da Alternância. Porém, por articularem-se o tempo todo com outros instrumentos no fazer pedagógico da instituição e na prática dos sujeitos, percebeu-se que não havia por que estabelecer uma hierarquia entre os diferentes instrumentos, já que todos são carregados de potencialidades, sendo capazes de incidir sobre as identidades sociais dos sujeitos.

\section{A produção das identidades/diferenças no CEFFA de Ji-Paraná}

O contexto educativo fundado na Pedagogia da Alternância vai constituindo os sujeitos, produzindo suas formas de ver e designar o que veem, interpelando-os para que ocupem determinadas posições de sujeito, o que os leva a identificar-se com alguns discursos, constituindo-se, assim, como alunos e monitores do CEFFA. Esses sujeitos estão sempre em processo de construção, pois, em se mudando as práticas sociais ou a forma como são trabalhadas, em se mudando os sujeitos que vão chegando, mudam-se as identidades; por meio dos discursos, novos significados vão sendo construídos, recrutando-os para novos posicionamentos.

Nas inter-relações no contexto do CEFFA, nas entrevistas com alunos e monitores e nos documentos curriculares, principalmente nos requisitos de acesso, no perfil do aluno que a Escola se propõe a formar (Plano de Curso, 2014) e nas Normas Internas, observa-se que há um "modelo" de aluno desejado. "A Escola procura tornar todo mundo igual”, como dizem os monitores Ana, Marcos e Sérgio, ficando "os alunos gays com medo de assumirem por causa da discriminação", como afirma a aluna Faith, ou "renegando os alunos diferentes", segundo o aluno Bruno. Dessa forma, durante o processo de formação dos sujeitos, quando estes diferem do padrão desejado, a Escola é encarregada de ir anulando as diferenças provocadoras de desequilíbrios. Skliar (2014) chama atenção para o fato de que "a descrição que se faz do sujeito diferente jamais coincide com ninguém, não há transparência ali, mas sim preconceito...” (p. 207).

No decurso da entrevista com o aluno José, este começa a falar como se tivesse feito uma descoberta, como se não tivesse ainda pensado sobre essas coisas. Parece surpreso com o achado. "Se somos iguais aqui, por que a Escola não tem alunos com deficiência física? ... Por que não tem alunos homossexuais ou pelo menos assumidos, não é? Deve ser porque não combina com os valores de nossas famílias". Ao inferir que a presença de homossexuais na Escola não combina com os valores das famílias agricultoras, o aluno José, por meio dos sentidos atribuídos à Escola, mostra que existe ali uma "nossa identidade”. Isso não ocorre só no CEFFA. Segundo Skliar (2014), "há nos cenários educativos uma indecisão ou uma confusão que se origina no instante em que as diferenças se fazem presentes e são nomeadas" (p. 206). Assim, pensando que a identidade e a diferença dependem da representação e que, como processos de produção social (Silva, 2012), estão envolvidas em relações de poder, esse aluno, forjado por uma Escola chamada da família agrícola, questiona em um primeiro momento a ausência dos que considera diferentes, quais sejam, deficientes e homossexuais. Porém, logo em seguida, assume a posição na qual se reconhece, apelando para antecedentes históricos, afirmando uma identidade que necessita, para o seu processo de construção, 
estar fundada em valores a partir dos quais a família camponesa foi historicamente construída.

Em alguns momentos, os sujeitos referem-se às diferenças em um plano mais comedido, mais complacente, como quando a aluna Débora afirma: "aqui na Escola, somos diferentes. Alguns são altos; outros, baixos. Uns mais falantes; outros, calados...”. Vê-se que isso parece não promover uma grande classificação entre os sujeitos, situando-os como marginalizados a partir da distinção "nós" e "eles". Enquanto isso, sendo as identidades constituídas, como já foi dito, em articulação com as diferenças, algumas dessas diferenças produzem uma capacidade de afetação maior a partir dos sistemas de representações em que estão inscritas, como quando o aluno Ney diz: "aqui, se a família do cara tiver dinheiro e ele for branco, não tem nenhuma dúvida de que o tratamento é outro"; ou quando o aluno Antônio fala que "a Escola não sabe lidar com as diferenças que tem dentro dela. Faz de conta que não existem". Essas diferenças, derivadas do contexto social em que se constituíram como tais, mostram que há preconceito, discriminação, agrupando os incluídos em um grupo "que deve ter outro tratamento”.

Tanto os monitores quanto os alunos são diferentes e trazem suas diferenças para a Escola, sendo ingênuo pensá-los como indivíduos genéricos (Bhabha, 2007). As identidades dos sujeitos da Pedagogia da Alternância vão sendo definidas por meio de um processo de produção da diferença, que nunca é definitivo; como produto social, a diferença é construída no contexto das relações sociais de poder (Silva, 2010). As falas, principalmente dos alunos, de que "uma das dificuldades aqui na Escola é sermos aceitos como somos, da nossa maneira” (José) e que "aqui na EFA, tem muito preconceito. Só que é bem camuflado" (Faith), expressam como o processo de representação vai impondo determinadas identidades, posicionando-os como sujeitos. Talvez por isso, a monitora Regina afirme: "acho que aqui na Escola não tem essa de alunos diferentes. Para mim, todos os alunos são iguais”.

Uma das questões que apareceram de forma bastante frequente, sobretudo nas entrevistas, foi a de os sujeitos da Escola se referirem a "diferença" e "desigualdade" como palavras que carregam sentidos que se assemelham, tratando-as, portanto, como termos que se equivalem, como se vê quando o monitor Marcos afirma: "a Escola procura tornar todo mundo igual, apesar de cada um ter as suas qualidades, as suas diferenças”. Nesse sentido, a diferença passa a ser vista como algo a não ser considerado, em nome do princípio da igualdade.

Cabe salientar que, na ótica dos Estudos Culturais, diferença e desigualdade não são sinônimos. A diferença opõe-se à homogeneização, e o contrário da igualdade é a desigualdade. Portanto, "a questão está em como trabalhar a igualdade na diferença” (Candau, 2008, p. 49). Assim, o termo "igualdade/desigualdade" serve para explicitar a condição socioeconômica dos sujeitos que, como agricultores migrantes para o interior de Rondônia, foram marginalizados pelas políticas públicas educacionais. Por isso, os alunos valorizam a Escola. "Aqui a gente aprende as coisas que precisa para mudar de vida e ter uma vida diferente da dos nossos pais" (Débora); "com os ensinamentos da Escola, eu posso mudar a forma atrasada com que a minha família trabalha a terra e cuida das criações” (José).

Se, do ponto de vista da desigualdade, o CEFFA parece desenvolver uma crítica pertinente, em relação à diferença, a pesquisa indica que ela é produzida como indesejável, sendo, inclusive, evitada durante a seleção dos alunos. Isso pode ser percebido quando a aluna Faith diz: "tem gente que, só de desconfiar que o colega é homossexual, já fica fazendo piadinhas, cutucando, querendo aparecer junto aos colegas”. Nas entrevistas, nota-se que há uma mar- 
ginalização dos considerados desiguais, pois, "se a família tiver dinheiro, o cara recebe outro tratamento", como disse o aluno Ney. Portanto, na Escola, circulam representações que vão sendo produzidas e reproduzidas, levando a preconceitos e inferiorizações que repercutem de forma aguda em alguns sujeitos.

Desse modo, pode-se afirmar que a Pedagogia da Alternância penetra na vida cotidiana e tem papel constitutivo na formação das identidades desses sujeitos, na tentativa de uniformização. Tudo deve ser agrupado, pressupondo a naturalidade da norma heterossexual e desclassificando qualquer outra forma de produção de identidade de gênero como infame, indecorosa, desconhecível. Quando os alunos dizem que "aqui eu tenho amigos gays, que não se assumem por causa de discriminação" (Faith), e que "eu já vi casos de preconceito aqui dentro por parte dos alunos pelo fato de a pessoa ser gorda, por ter um aspecto afeminado, ser peluda ou muito feia" (Antônio), confirma-se essa incapacidade de conviver com a diferença, de vê-la como um processo de produção criado e recriado pelos sistemas dominantes de representação, de percebê-la como fonte de diversidade, heterogeneidade e hibridismo, resgatando as identidades sexuais dos constrangimentos da norma e celebrando a diferença (Woodward, 2012).

Como humanos, somos apenas diferenças, como diz Bauman (2007), pois "existem milhares de homens e mulheres no planeta, mas cada um deles é diverso dos outros. Não existem indivíduos totalmente idênticos, isso é impossível. Existimos porque somos diferentes, porque consistimos em diferenças" (p. 95). Apesar de, "na Escola, todo ano chegarem alunos totalmente diferentes", como diz o monitor Marcos, ela tenta ignorar as diferenças e, mesmo quando os diferentes se mostram, a forma de lidar com "eles", de mostrar que são intoleráveis, é sutil, disfarçada ou tratada como "brincadeiras que não machucam o colega", segundo a monitora Sara. O monitor Sérgio ratifica essa posição da Escola: "a questão do gordo, do magro, do preto, do branco, tem o sarro, mas não é por preconceito. É por pura amizade. Até os monitores chamam de 'gordo', de 'neguinho', mas não é por maldade”.

Os monitores afirmam que o ambiente do CEFFA, regulado pelas Normas Internas, favorece o convívio entre os diferentes. Esclarece-se que neste artigo não foi possível fazer uma análise minuciosa das normas da Escola, mas há um documento, conhecido pelo nome de Normas Internas, que serve para regular/controlar a convivência na Pedagogia da Alternância. Essas normas referem-se a um conjunto de práticas, tais como proibição do uso do celular e furtos, uso de vestimentas adequadas, cumprimento de horários, participação nas tarefas de limpeza, cuidado com a higiene pessoal, etc. O documento foi elaborado pela Associação Promocional da Escola, e, nos seus 95 artigos, consta o que o aluno pode e não pode fazer, estabelecendo-se, ainda, a punição para cada "infração". Como os jovens de hoje são "maquiavélicos", como diz o monitor Sérgio, e buscam, na convivência e nas amizades com os colegas, meios de ficar "tramando" (Marcos), o CEFFA procura conter as indisciplinas por meio das Normas Internas, ou seja, primeiro, criou-se o perfil do aluno transgressor, indisciplinado, inadequado; depois, criaram-se as normas, que atuam no sentido de produzir os alunos como o CEFFA previu.

Cabe destacar que, mesmo que os monitores afirmem que as Normas garantem a boa convivência com os diferentes, a pesquisa indica que os processos de discriminação que existem em função das diferenças não são percebidos: "é um modo de tratamento entre eles, não é questão de preconceito para desmerecer o outro", como diz o monitor Sérgio. Assim, os alunos, quando mostram as diferenças, estas são vistas como estorvos transitórios (Bauman, 2011), como se vê na fala do aluno Antônio: "a Escola não sabe lidar com as diferenças 
que tem dentro dela... Eu já vi casos de preconceito aqui dentro”. Mesmo furtiva, a diferença na Escola a cada dia vai se impondo como uma necessidade pedagógica de desenvolver novas artes e habilidades, de ensiná-las, de aprendê-las (Bauman, 2011). A monitora Regina chega a dizer que "é bom não ver isso como problema", no que é confirmada pela aluna Faith: "é melhor fazer de conta que isso não está acontecendo".

Pelas observações realizadas de fevereiro a novembro de 2016, é possível afirmar que, na sala de monitores, quando a conversa gira em torno desses "alunos diferentes", fica visível a existência de uma identidade de aluno do CEFFA, que, para ser mantida, requer vigilância permanente. Sobre a matrícula de alunos especiais, a monitora Sara afirma: "se já temos tantos problemas com esses alunos do jeito que são, imagine se começar a chegar alunos com deficiências maiores. O que seria da Escola?”. Assim, há o reconhecimento de que existem alunos diferentes, mas, como na Escola não há espaço para eles, estes devem adequar-se aos padrões da instituição. Nas entrevistas, ao serem questionados por que não há espaço para os diferentes, os monitores afirmaram que lhes falta preparação, formação para lidar com as diferenças, principalmente sexuais, e que o CEFFA não tem estrutura física compatível, como, por exemplo, banheiros e dormitórios para os homossexuais. Como se observa, os banheiros e os dormitórios para os heterossexuais (masculino e feminino) são a norma; outros banheiros, outros dormitórios, quebram a norma. Isso demonstra que "a identidade subordinada é sempre um problema: um desvio da normalidade. Ela é, sempre, a identidade marcada" (Silva, 2010, p. 49).

Os monitores (Ana, Sérgio, Marcos e Sara) afirmam que não tiveram uma formação para o reconhecimento dos diferentes, "desses invisíveis", dos incômodos. Segundo Bauman (2007), não é de se estranhar que os sujeitos encarem com horror cada vez maior a perspectiva de se confrontarem cara a cara com estranhos - no caso dos monitores, com aqueles que não aparecem sequer nos requisitos de acesso da Escola, explicitados no Plano de Curso (2014). Esses monitores, em parte forjados pela Pedagogia do CEFFA, não se depararam, em suas formações, em cursos ou em estudos teóricos, com experiências que lhes permitam lidar com o que não são. Procuram, então, manter os diferentes à distância. Quando não dá para ignorá-los, visto que, quando os diferentes se fazem presentes, tendem a parecer mais e mais assustadores à medida que se tornam mais desconhecidos e incompreensíveis (Bauman, 2007), ignoram os efeitos das inter-relações em que se envolvem ou se colocam na posição de observadores tolerantes, pois, se há preconceito no CEFFA, deve-se à maneira como os alunos foram constituídos. A fala das monitoras mostra isso: "são brincadeiras que não machucam o colega" (Sara); "eles não ficam ofendidos, pois sabem que é carinhoso" (Ana).

Dentre os monitores ouvidos, somente Carlos declarou que há preconceito e discriminação no CEFFA. Afirma que já presenciou muitos preconceitos em brincadeiras ofensivas, como, por exemplo, "chamar o aluno de 'macaco' ou 'seu macaquinho', vai comer banana". Porém, quando perguntado sobre o que se faz na Escola com essas brincadeiras ofensivas e apelidos pejorativos, o monitor afirma que "fica por isso mesmo".

Ao analisarem-se as falas de alunos e monitores, pode-se perceber que a afirmação de uma identidade de estudante do CEFFA se dá em depreciação àquelas que não deveriam ocupar esse espaço, ou seja, afirmam-se no mesmo espaço-tempo as identidades e as diferenças. Só que, ao estabelecer-se uma identidade como parâmetro, esta é privilegiada em detrimento de algumas diferenças, que podem ser obscurecidas (Woodward, 2012). A aluna Faith afirma que "tem muito preconceito na Escola" e que "os alunos gays têm medo de 
assumir por causa da discriminação". E continua: "eu sei de pessoas que vivem esse dilema na EFA. Mas a Escola prefere fazer de conta que isso não está acontecendo". Inclusive o monitor Carlos lamenta: "a Escola não pode maltratar o aluno por causa de sua diferença, mas maltrata". Fica visível que, no CEFFA, os sujeitos vão negociando suas identidades, visto que, ao assumirem determinadas posições de identidade e identificarem-se com elas (Woodward, 2012), precisam garantir sua manutenção e tendem a enquadrar-se na identidade desejada.

Os sentidos que os alunos produzem no curso de suas atividades dentro do CEFFA são plurais, ambivalentes, cambiantes. Apesar do que foi mostrado na pesquisa, grande parte dos entrevistados afirma que não há preconceito nem discriminação no CEFFA. Isso mostra uma instituição como um campo de luta em torno da imposição dos significados, onde práticas de significação, de identidade e de poder se entrecruzam (Silva, 2010). As diferenças podem ter se tornado invisibilizadas, e há no CEFFA uma aspiração à homogeneidade. Ignora-se a instabilidade, a fluidez com que as identidades são produzidas na relação com as diferenças.

\section{Considerações finais}

Pela pesquisa efetuada, pode-se afirmar que o CEFFA, a partir de um padrão de normalidade criado ao longo dos anos para dar sentido ao seu fazer pedagógico, materializado no seu projeto curricular, opera na produção de identidades marcadas, formadas relativamente a outras identidades, "desviantes", que precisam ser mantidas à distância, invisibilizadas ou "suavizadas" na forma como são tratadas. O preconceito e a discriminação são percebidos como brincadeiras "inocentes”, pois os diferentes desagregam a pretensa regularidade com a qual "sonham" os que ocupam determinadas posições de sujeito em meio a relações de poder na Pedagogia da Alternância.

Entretanto, o processo de normalização, de fixação de uma identidade vista como a identidade do sujeito da Pedagogia da Alternância, tem sido constantemente desestabilizado pela presença dos diferentes ou pela sua exclusão por não atenderem ao perfil de admissão. Há momentos nos quais tanto os monitores quanto os alunos questionam a Pedagogia da Alternância, o que mostra que não é uma prática cristalizada, mas sujeita a mudanças.

Ao finalizar-se este artigo, esclarece-se que, recorrendo-se aos Estudos Culturais e à sua interface com a Psicologia Social para problematizar a Pedagogia da Alternância, não se intencionou colocar em xeque a importância de projetos educativos alternativos que abrem novas possibilidades de significação, outras práticas políticas, produzindo outras identidades e diferenças, dessemelhantes das até então produzidas pela escola rural. A opção por fazer a análise de um projeto como o do CEFFA é por considerar que efetivamente traz alternativas, pois consegue romper, pelo menos em parte, com o modelo, com o currículo sob o qual até hoje os agricultores e seus filhos foram educados.

Esclarece-se, ainda, que com essa pesquisa não se intentou argumentar que o CEFFA não contribui para produzir um sujeito que afirma sua identidade e cultura e que toma ciência dos processos de construção das desigualdades. O que se mostrou é que, em relação às diferenças, sua prática é normalizadora. Ao privilegiar a produção de uma identidade, sem problematizar tal produção na relação com as diferenças, acaba por produzir algumas 
diferenças como indesejáveis e desviantes. Nesse sentido, um olhar de fora, como é o olhar dos Estudos Culturais, em articulação com a Psicologia Social, dado que os Princípios da Pedagogia da Alternância não estão inspirados nesses campos teóricos, possibilitou mostrar que essa proposta pedagógica tem um modo específico de produzir identidades e diferenças, e que os sujeitos vão sendo posicionados, cada qual de acordo com um nível de afetação, constituindo-se a partir das práticas e artefatos culturais com os quais se relacionam, ressignificando-os.

\section{Referências}

Arroyo, M. (2014). Outros sujeitos, outras pedagogias. Petrópolis, RJ: Vozes.

Bauman, Z.(2007). Tempos Líquidos. Rio de Janeiro: Zahar.

Bauman, Z. (2011). 44 Cartas do mundo líquido moderno. (V. Pereira, Trad.). Rio de Janeiro: Zahar.

Bhabha, H. K. (2007). O local da cultura. (M. Ávila, E. L. L. Reis, \& G. R. Gonçalves, Trad.). Belo Horizonte: UFMG.

Bernardes, A. G. \& Hoenisch, J. C. D. (2013). Subjetividades e identidades: possibilidades de interlocução da Psicologia Social com os Estudos Culturais. In N. M. F. Guareschi \& M. E. Bruschi (Orgs.), Psicologia Social nos Estudos Culturais. Perspectivas e desafios para uma nova Psicologia Social (pp. 94-124). Petrópolis, RJ: Vozes.

Candau, V. M. (2008). Direitos humanos, educação e interculturalidade: as tensões entre igualdade e diferença. Revista Brasileira de Educação 13(37), 45-56. Recuperado de http://www. scielo.br/pdf/rbedu/v13n37/05.pdf.

Escosteguy, A. C. D. (2010). Cartografias dos Estudos Culturais. Uma versão Latinoamericana (ed. on-line ampl.). Belo Horizonte: Autêntica.

García-Marirrodriga, R. \& Puig-Calvó, P. (2010). Formação em alternância e desenvolvimento local. O movimento educado dos CEFFA no mundo. Belo-Horizonte: O Lutador. (Coleção AIDEFA)

Gimonet, J. C. (2007). Praticar e compreender a Pedagogia da Alternância dos CEFFAs. Petrópolis: Vozes. (Col. AIDEFA).

Guareschi, N. M. F., Medeiros, P. F., \& Brushi, M. E. (2013). Psicologia Social e Estudos Culturais: rompendo fronteiras na produção do conhecimento. In N. M. F. Guareschi \& M. E. Bruschi (Orgs), Psicologia Social nos Estudos Culturais. Perspectivas e desafios para uma nova Psicologia Social (pp. 23-49). Petrópolis, RJ: Vozes.

Hall, S. (1997). A centralidade da cultura. Educação E゚ Realidade, 22(2), 15-46.

Hall, S. (2012). Quem precisa de identidade? In T. T. Silva. (Org.), Identidade e diferença. A perspectiva dos Estudos Culturais (12 ${ }^{\mathrm{a}}$ ed., pp.103-130). Petrópolis, RJ: Vozes.

Hall, S. (2013) Da diáspora: identidades e mediações culturais (2ª ed.). Belo Horizonte: Editora UFMG.

Hall, S. (2016). Cultura e representação. Rio de Janeiro: Apicuri.

IBGE.(2014). Cidades: Estimativa da População de 01 de julho de 2014. (Rondônia. Ji-Paraná). Recuperado de http://www.ibge.gov.br/home/estatistica/populacao/estimativa2014/estimativa tcu.shtm.

Meyer, D. E. \& Soares, R. F. (2005). Modos de ver e de se movimentar pelos “caminhos” da pesquisa pós-estruturalista em Educação: o que podemos aprender com - e a partir de - um filme. In M. V. 
Costa \& M. I. E. Bujes (Orgs.), Caminhos investigativos III: riscos e possibilidades de pesquisar nas fronteiras (pp. 23-44). Rio de Janeiro: DP\&A.

Nosella, P. (2013). A formação pelo trabalho. In J. B. Begnami \& T. Burghgrave (Orgs.), Pedagogia da Alternância e sustentabilidade (pp. 95-103). Orizona, Go: UNEFAB (Coleção Agir e Pensar das EFAs do Brasil)

Nosella, P. (2014). Origens da Pedagogia da Alternância no Brasil. Vitória: EDUFES. (Coleção Educação do Campo. Diálogos Interculturais)

Puig-Calvó, P. \& Gimonet, J. C (2013). Aprendizagens e relações humanas na Formação por Alternância. In J. B. Begnami \& T. Burghgrave (Orgs.), Pedagogia da Alternância e sustentabilidade (pp. 35-69). Orizona, Go: UNEFAB. (Coleção Agir e Pensar das EFAs do Brasil)

Queiroz, J. B. P. (2013). O estado da arte da Alternância no Brasil. In J. B. Begnami \& T. Burghgrave (Orgs.), Pedagogia da Alternância e sustentabilidade (pp. 137-165). Orizona, Go: UNEFAB. (Coleção Agir e Pensar das EFAs do Brasil)

Silva, T. T. (2010). O currículo como fetiche. A poética e a política do texto curricular. Belo Horizonte: Autêntica.

Silva, T. T. (2012). A produção social da identidade e da diferença. In T. T. Silva (Org.), Identidade e diferença. A perspectiva dos Estudos Culturais (12 ${ }^{\mathrm{a}}$ ed., pp. 73-102). Petrópolis, RJ: Vozes.

Skliar, C. (2014). Desobedecer a linguagem. Educar (G. Lessa, Trad.). Belo Horizonte: Autêntica. (Coleção Educação: Experiência e Sentido)

Souza, M. M. (2014). Imperialismo e Educação do Campo. Araraquara, SP: Cultura Acadêmica.

Woodward, K. (2012). Identidade e diferença: uma introdução teórica e conceitual. In T. T. Silva (Org.), Identidade e diferença. A perspectiva dos Estudos Culturais. (12 ed., pp. 7-72). Petrópolis, RJ: Vozes.

\section{ALBERTO DIAS VALADÃO \\ https://orcid.org/0000-0002-5969-935X}

Professor do Departamento de Ciências Humanas e Sociais - UNIR - Campus de Ji-Paraná.

Endereço: Rua das Flores 143, Bairro Dois de Abril, CEP: 76900-814, JiParaná/RO

E-mail: albertoelaine10@gmail.com

\section{JOSÉ LICÍNIO BACKES}

https://orcid.org/0000-0001-9013-8537

Doutor em Educação. Professor do Programa de Pós-graduação em Psicologia - UCDB. Bolsista Produtividade CNPq.

E-mail: backes@ucdb.br 


\begin{tabular}{ll}
\hline Histórico & Submissão em: 27/11/2017 \\
& Revisão: 11/12/2018 \\
& Aceite em: 07/03/2019 \\
& Concepção: A. D. V.; J. L. B. \\
& Coleta de dados: A. D. V. \\
& Análise de dados: A. D. V.; J. L. B. \\
& Elaboração do manuscrito: A. D. V.; J. L. B. \\
& Revisões de conteúdo intelectual importante: A. \\
& D. V.; J. L. B. \\
Contribuição dos autores & Aprovação final do manuscrito: A. D. V.; J. L. B. \\
& Alberto Dias Valadão teve Bolsa PROSUP/CAPES. \\
& José Licínio Backes é Bolsista Produtividade do CNPq. \\
Financiamento & Não se aplica \\
\hline \multirow{2}{*}{ Consentimento de uso de imagem } & O estudo foi aprovado pelo Comitê de Ética da \\
Aprovação, ética e consentimento & Universidade Católica Dom Bosco. N ${ }^{\circ}$ CAAE: \\
& 51173315.9 .0000 .5162 - Parecer: 1350322.
\end{tabular}

